In course of time the river mouth passed this channel and blocked it up, so the Tour de Tampan was abandoned and a new one, the Tour de St. Genest, was built, in r656, on what was evidently an island of the old land surface of Roman times, and not far from the spot where the boundary stone with Latin inscription was discovered in $\mathrm{I} 883$.

This tower, at last, lay close to the sea-face of the delta; the most advanced outpost of the old land was not much more than a mile to the southwards, and, when the river extended past this point, it no longer ended in a sheltered inlet, but in the open sea. The formation of an extension of the delta, by the silt brought down the river, began, and a difficult and dangerrous bar developed, the hindrance to navigation becoming more acute as the river mouth was pushed farther out into the open sea. Many schemes and proposals for remedying this were considered, during the latter half of the seventeenth century, but none had been initiated when, in $\mathrm{x} 7 \mathrm{x}$, the river broke away along the line of the old navigable channel, past the site of the Tour de Bolovard, to enter the sea close by the place where, in 1737 , the Tour St. Louis was built, close to the sea-face of the land, as it then stood. Since then there has been no further change in the channels farther up- stream, and the whole river is so firmly controlled by protective embankments that none is likely to occur.

From this brief history it appears that the mouth of the Rhone, which was near Passon about the middle of the fifteenth century, had advanced to the present coast-line at the Vieux Rhône by the middle of the seventeenth, and early in the following century was at the coast-line of that time near the modern town of St. Louis. This advance of the mouth of the river does not, however, mean a growth of the delta by a depth of ten kilometres along a breadth of about twenty ; this would mean an increase of nearly a square kilometre a year, fully five times the rate of growth of the delta during the last two centuries. It was, however, not from the open sea that the land was reclaimed, but from a number of shallow channels separating islands of old alluvium, thus reducing largely both the area and depth of the new deposits, and in this way the changes, which are known to have taken place, are not merely to be explained by subsidence of the land during the Dark Ages, but in themselves become evidence of the reality of the change of level, independently deduced from evidence of a wholly different character.

(To be continued.)

\title{
Two New Elements of the Manganese Group.
}

THE recent discovery of the two missing elements of the manganese group by Dr. Noddack and Fräulein Tacke of Berlin is of interest not only as an important step towards the completion of the periodic table but also on account of the methods used in the research. In these days no one branch of science can afford to stand aloof from the others, and perhaps it would be difficult to find a happier example of the way in which the various sciences can combine towards a successful result than this discovery of the eka-manganeses. Chemistry, physics and mineralogy have all played their parts, and the result is that the number of gaps between hydrogen and uranium in the periodic table has been reduced from five to three.

In the preliminary account of their work which has been published in Die Naturwissenschaften for June 26, p. 567 , the authors give, in addition to the results of their investigations, the arguments on which their line of attack was based. In the first place, it was necessary to find some material in which the new elements might reasonably be expected to occur. A study of the neighbouring elements suggested two possible sources; the first that of the platinum ores, the second a mineral such as columbite. The platinum ores contain the elements chromium to copper, ruthenium to silver, osmium to gold, or, expressed in atomic numbers, 24 to 29, 44 to 47 , and 76 to 79 . Columbite, on the other hand, contains, among many other elements, those of atomic number 39 to 42 and $7 x$ to 74 . Here, therefore, were two minerals in either of which the missing elements 43 and 75 might well be found.

In endeavouring to form an estimate of the amounts of the elements 43 and 75 which might be present in these minerals, the authors employed an ingenious argument. The constitution of the earth's crust is now fairly well known, and it is possible to assign to the various elements numbers indicating the frequency of their occurrence. A study of these figures indicates that elements of odd atomic number are less common than those of even atomic number; in fact, an odd element is ten or twenty times less abundant than the succeeding even element. As ruthenium (44) and osmium $(76)$ constitute about $2 \times 10^{-12}$ and $2 \times 10^{-11}$ of the earth's crust, it was deduced that the elements 43 and 75 would form about $10^{-13}$ and $10^{-12}$ of the earth's outer layer. As the frequency of occurrence of platinum is $10^{-9}$, the amount of the elements 43 and 75 in the platinum ores should be from $\mathrm{ro}^{-3}$ to $10^{-4}$, and as niobium, one of the chief constituents of columbite, forms $10^{-7}$ of the earth's surface, columbite was estimated to contain from $10^{-5}$ to $10^{-6}$ of the missing elements. In this way Drs. Noddack and Tacke obtained some idea of the extent to which the chemical processes of extraction would have to be carried if measurable quantities of the new substances were to be obtained.

It was a fairly straightforward matter to predict some of the chemical properties of the new elements from a consideration of their neighbours in the periodic table. Thus it appeared probable that both would form oxides $\mathrm{X}_{2} \mathrm{O}_{7}$, and that these oxides would readily sublime on account of the small difference of temperature between their melting- and boiling-points. Again, for example, it was argued that the eka-manganeses would resemble chromium in so far as no sulphides would be formed from aqueous solutions. These and other chemical properties were used in the chemical treatment of the ores.

Attention was first directed to the platinum ores as offering the highest chance of success. After preliminary chemical treatment, the residue of $80 \mathrm{gm}$. of a Russian ore was strongly heated alternately in oxygen and hydrogen. Among the deposits on the walls of the vessel was found a very small quantity of white microscopic needle crystals. These needles became dark in 
colour when treated with a stream of hydrogen sulphide, while a subsequent heating in oxygen resulted in the reappearance of the white sublimation product on the colder part of the vessel. An aqueous solution of these crystals gave no precipitate either with hydrogen sulphide or ammonium sulphide. As such behaviour was to be expected from the elements 43 and 75 and from none of the other known elements in the solution, it was presumed that this substance contained the missing elements. Further attempts at concentration resulted in a loss of the material.

Through lack of further supplies of the platinum ores, the authors turned their attention to columbite, resolving at the same time to carry out the final analysis by X-rays. From about I $\mathrm{kgm}$. of the mineral the greater part of the iron, niobium and tantalum was removed by sodium hydroxide and sodium nitrate ; the filtered solution was treated with hydrogen sulphide and concentrated to a volume of 50 c.c. By the use of mercurous nitrate, about one gram of precipitate was obtained from this solution. A repetition of the process gave about $50 \mathrm{mgm}$., estimated to contain about 5 per cent. of the elements 43 and 75 . Heating in oxygen gave once more the white sublimate. The quantity available was too small for direct application to the anticathode of the X-ray tube. It was, therefore, mixed with niobic acid and examined spectroscopically in this form.

$\mathrm{X}$-ray spectra probably provide the best method for the detection of a small quantity (say 0.1 per cent.) of an element in a mixture. These spectra are much simpler in nature than the optical spectra, and, unlike the latter, do not depend on the mode of excitation or on the state of chemical combination. The wavelengths are determined by the atomic number alone. From Moseley's laws it is possible to predict the wavelengths of the various lines with considerable accuracy. A further check is provided by an examination of the relative intensities of the lines. An X-ray investigation of the final products of the chemical processes was carried out by Drs. Berg and Tacke, and a search made for the $K$ series of the element 43 and for the $L$ series of 75 . The result was entirely successful. Three lines appeared on the plates corresponding to wave-lengths $0.601,0.672$ and $0.675 \AA$.U., whereas the calculated values of the $K \beta_{1}, K \alpha_{1}$ and $K \alpha_{2}$ lines for an element 43 are $0.600,0.673$ and $0.678 \AA . U$. These are the three strong lines in the $K$ series, and their relative intensities agreed with the well-known ratios. In the spectral region $\mathrm{I} \cdot 20$ to $\mathrm{I} \cdot 43 \AA$.U. there occurred five lines which were identified as the $L \alpha_{1}, L \alpha_{2}, L \beta_{1}, L \beta_{2}$ and $L \beta_{3}$ lines of an element of atomic number 75 . The numerical agreement was excellent; thus, the observed and calculated wave-lengths of the $L \alpha_{1}$ line were I.4299 and I.4306 A.U. There is always a chance that the lines may be wrongly identified, but the authors appear to have taken due precautions against any possible misinterpretation, and there seems no doubt that these lines are actually due to the presence in the columbite residue of the elements 43 and 75 .

As a result of this careful research work, the existence on the earth of the elements of atomic number 43 and 75 appears to be definitely established, a fact which is all the more interesting because certain writers have put forward arguments suggesting that a search for the eka-manganeses must prove fruitless. The actual amount of the new elements in columbite is estimated as from $10^{-6}$ to $10^{-7}$, or somewhat less than the proportion indicated by the calculations outlined above. The chemical and physical properties appear to be closely related to those predicted by an examination of their neighbours, but no doubt more details will soon be available when greater quantities of the new elements have been isolated.

The authors suggest that the two newly discovered elements should be named Masurium (Ma) and Rhenium $(\mathrm{Re})$ after the district of Eastern Prussia and after the Rhine respectively. Whether these names will meet with such widespread approval as the research itself remains to be seen.

\section{Current Topics and Events.}

IN celebration of the 250 th anniversary of the foundation of the Royal Observatory, Greenwich, their Majesties the King and Queen will pay a visit to the Observatory on July 23. We understand that they will be received in the Octagon Room, the otiginal Observatory, by members of the Board of Admiralty and of the Board of Visitors of the Royal Observatory, and will then be conducted over the buildings and shown the principal instruments. On the evening of the same day a conversazione is being given by the president and council of the Royal Society to meet the delegates to the International Astronomical Union. On the following day an official luncheon is being given, presided over by the First Lord of the Admiralty.

AFTER nearly two years' effort, the Australian National Research Council has succeeded in its project for establishing a Commonwealth School of Anthropology, to be attached to the University of Sydney. In December I923 the Commonwealth Government expressed approval of a scheme sub- mitted to it; in the following year, however, an officer selected by the British Government to advise Australia in the matter of administration of Territories, reported very strongly against the proposal to use such a school for the training of officials. In consequence, Government interest flagged. Renewed efforts, supported by the Australasian Association for the Advancement of Science and the universities, were made in September, and, largely as the result of a visit from Prof. Elliot Smith, who brought unofficial word of warm American sympathy, the Prime Minister promised to provide roool. per annum towards the expenses of a chair. The estimated yearly requirement being $2500 l$., the respective States were then asked to contribute the balance of $1500 l$. between them on a population basis. New South Wales, Victoria, Queensland and Tasmania agreed to provide their shares, and South Australia is practically certain to fall into line ; Western Australia remains uncertain. The Research Council, therefore, has now asked the Senate of the University of Sydney to consider the immediate appointment of a professor 